\title{
Family Structure and Child Well-Being in a Non-western Context: The Role of Parent-Child Relations and Parental Conflict in South Korea
}

Jonathan A. Jarvis

Brigham Young University - Provo

Ashley Larsen Gibby

Brigham Young University - Provo, ashley_gibby@byu.edu

Mikaela J. Dufur

Brigham Young University - Provo

Shana Pribesh

Old Dominion University

Follow this and additional works at: https://scholarsarchive.byu.edu/facpub

Part of the Other Social and Behavioral Sciences Commons

\section{Original Publication Citation}

Jarvis, Jonathan A., Ashley Larsen Gibby, Mikaela J. Dufur, and Shana L. Pribesh. 2020. "Family Structure Change and Behavioral Problems in South Korea." Population Research and Policy Review 39(3).

\section{BYU ScholarsArchive Citation}

Jarvis, Jonathan A.; Gibby, Ashley Larsen; Dufur, Mikaela J.; and Pribesh, Shana, "Family Structure and Child Well-Being in a Non-western Context: The Role of Parent-Child Relations and Parental Conflict in South Korea" (2020). Faculty Publications. 4795.

https://scholarsarchive.byu.edu/facpub/4795

This Peer-Reviewed Article is brought to you for free and open access by BYU ScholarsArchive. It has been accepted for inclusion in Faculty Publications by an authorized administrator of BYU ScholarsArchive. For more information, please contact ellen_amatangelo@byu.edu. 


\title{
Family Structure and Child Well-Being in a Non-western Context: The Role of Parent-Child Relations and Parental Conflict in South Korea
}

\author{
Jonathan A. Jarvis ${ }^{1}$ (D) Ashley Larsen Gibby ${ }^{2}$ (D) Mikaela J. Dufur ${ }^{1}$ (D) \\ Shana Pribesh ${ }^{3}$ (iD
}

Received: 25 September 2018 / Accepted: 25 April 2020 / Published online: 1 May 2020

(c) Springer Nature B.V. 2020

\begin{abstract}
Research suggests that children who live with two biological married parents are less likely to exhibit behavioral problems than children who do not. While research on childhood outcomes often focuses on the nature of the family structure itself, recent studies have pointed to relationship quality between parents, and between parents and children, as important mechanisms through which family structure affects children. However, the independent influence of these two mechanisms-relationship quality between parents and between parents and children-on childhood outcomes has never, to our knowledge, been tested outside of a high-income western environment. Using the Korean Youth Panel Study (KYPS), we use cross-sectional and longitudinal GEE models to examine the influence of family structure, parent-child relationship quality, and parental conflict on internalizing and externalizing behavior problems among 2844 adolescents in South Korea, a high-income, non-western context with relatively little family structure instability. We found that family structure, parental conflict, and parent-child relationship quality were all significantly related to child well-being. Children living in family structures other than with their two married biological parents were more likely to report internalizing and externalizing behavioral problems. Further, parental conflict was negatively related to child wellbeing, while parent-child relationship quality was positively related to child wellbeing. These findings show that interpersonal relationships are important to children across family structures and should be included in studies examining how families impact child well-being. Our study also reinforces the importance of looking at family structures and processes in non-western contexts.
\end{abstract}

Keywords Family structure change $\cdot$ Parent-child relations $\cdot$ Parental conflict . Child behavioral problems $\cdot$ Korea

Jonathan A. Jarvis

jonathan_jarvis@byu.edu

Extended author information available on the last page of the article 


\section{Introduction}

Research on family structure suggests that children who live with two biological married parents are less likely to experience behavioral problems than children who do not, despite the normalization of non-traditional family structures in many highincome, western countries (Lee and McLanahan 2015; Hoffmann 2017). In highincome, non-western nations, such as Taiwan, Singapore, and South Korea, where divorce rates have historically been much lower than in western nations (Chen and Yip 2018; OECD 2018a), non-traditional family structures remain less common and attitudes towards divorce more negative (Eun 2007). While the positive effects for children living in two-parent married families are generally agreed upon, the mechanisms through which family structure affects childhood outcomes are less clear, especially in these non-western nations where family structure has been more stable. Recent studies increasingly point to the role of relationship quality between parents, and between parents and children, in explaining positive child outcomes.

Although an in-depth literature connects relationship quality, family structure, and child outcomes (e.g., Amato and Keith 1991; Booth and Amato 2001; Yu et al. 2010), this literature is limited in three major ways. First, many studies conceptualize household conflict and relationship quality at the parent level (among parents themselves); however, few consider relationship quality at the parent-child level. Second, the influence of parent-child relationship quality on behavioral outcomes, independent of parental conflict and family instability, has rarely been tested. Third, these studies are almost solely focused on western nations where divorce and family instability are relatively high. In order to assess the universality of such findings, studies in non-western nations are needed.

Using data from the Korean Youth Panel Study (KYPS) gathered from youth in South Korea (hereafter Korea), we estimate cross-sectional regression and longitudinal generalized estimating equation (GEE) models to examine the independent influences of family structure, parent-child relationship quality, and parental conflict on internalizing and externalizing behaviors among Korean children. We address the aforementioned gaps in the literature with the following questions: (1) to what extent does parent-child relationship quality account for the association between family structure and child behavior? and (2) how do parent-child relationship quality, parental conflict, and family structure affect child behavioral problems, independently of each other? Examining these patterns among Korean children also provides a window into how these processes operate in contexts with very different family structure instability patterns than those in the better-understood western context.

\section{Family Structure and Child Outcomes}

A robust literature connects family structure to a variety of child outcomes, including educational achievement and attainment, deviance and delinquency, and later family formation (see Brown's 2010 review). Of particular interest are children's mental and emotional health, as living in family structures with access to both 
biological parents has a negative association with a number of health challenges, such as eating disorders and attention deficit hyperactivity disorder (Carballo et al. 2013). Family structure appears to affect childhood outcomes, whether the biological parent is removed by marital or relationship dissolution (Kim 2011), by death (Amato and Anthony 2014), by military deployment (Gorman et al. 2010), by immigration (Creighton et al. 2009), or by incarceration (Wildeman et al. 2013). In addition, children who lose access to a parent are often exposed to additional related stressors, such as having to move from a shared family home (Pribesh and Downey 1999; McCulloch et al. 2000). These changes in family structure are associated with problematic behavior in children (McLanahan and Sandefur 1994; Hoffmann 2002, 2017), patterns that are generally attributed to factors related to marital disruption and family structure change, such as decreased familial resources (Thomson and McLanahan 2012), stressors related to transition and instability (Waldfogel et al. 2010; Lee and McLanahan 2015), and selectivity issues related to family structure and parenting (Dufur and Alexander 2017).

Beyond a child's current family structure, transitions into and out of family structures during a child's life are also critical for child outcomes. Research has found that family instability can negatively affect child outcomes (Waldfogel et al. 2010), perhaps most negatively for children transitioning out of two-parent families (Lee and McLanahan 2015). While research has examined the effects of family stressors associated with the removal of a parent, adding a parental figure causes stress on children as well (Fomby and Cherlin 2007; Bachman et al. 2011). This may be a result of residential moves or the negotiation of new family guidelines (Aquilino 2006).

\section{The Role of Conflict}

It is also possible that family processes related to but distinct from family structure instability contribute to these negative outcomes. Beyond instability and family structure, parental conflict may contribute to negative child behavior. Conflict is an integral part of the negative impact of divorce on child outcomes (Amato and Keith 1991; Amato et al. 1995). Marital conflict lowers closeness with parents, and divorce lowers it further (Booth and Amato 2001). Parental conflict leading up to and during marital disruption can also be extremely stressful for children (Cummings et al. 1981; Cummings 1987), which is associated with a number of negative outcomes.

Some researchers have concluded that the presence of conflict between parents is so damaging that it outweighs the effects of family transitions. Supporting this conclusion, several studies have found that children in intact but high-conflict family structures actually exhibit more behavior problems than children in high-conflict disrupted family structures (Amato and Keith 1991; Cherlin et al. 1991; Jekielek 1998; Morrison and Coiro 1999), perhaps because they are exposed to ongoing conflict. This research suggests that there is a spectrum, or rank order, of well-being for children ranging from two-parent intact families with low conflict as the best environment for a child, to twoparent intact families with high-conflict families as the most problematic (Amato et al. 
1995). Therefore, while divorce is a negative experience for children, it might be more desirable for children than remaining in an intact two-parent family with high levels of conflict. Disruption may even be a form of stress relief for children in high-conflict environments (Wheaton 1990).

Other studies, however, show that separation and divorce lead to problem behaviors regardless of parental conflict (Morrison and Coiro 1999). These findings contribute to a mixed picture of how family transitions and exposure to parental conflict work independently and together to increase child problem behavior. Further complicating our understanding, these mixed findings have focused almost entirely on western contexts with relatively high rates of family instability. The role of parental conflict in child behavior problems in low-divorce settings remains unknown. It is possible that in such contexts, parental conflict is even more influential on problem behavior, as the stress relief associated with divorce (Wheaton 1990) is less available to troubled families. On the other hand, divorce and living in non-traditional family structures in these contexts may be so non-normative that experiencing such transitions becomes especially difficult.

\section{Parent-Child Relationships}

In addition to having a direct effect on children's behavior, both family structure transitions and exposure to parental conflict likely have a negative association with the relationships between parents and children. Shifts in parenting during high-conflict circumstances or during family dissolution, when parents may become distracted, depleted, or preoccupied (Amato and Booth 1996), may damage pre-existing parent-child relationships. Parental conflict can also lead to parent-child relations changing as family boundaries thin and children become too involved in adult issues (for a review, see Cox and Paley 1997). Resentment about family dissolution or stressors generated by having to adjust to new residential and family circumstances may damage communication and trust between children and parents (Erel and Burman 1995; Kouros et al. 2014; Braithwaite et al. 2015). Given these patterns, it is surprising that few representative studies explore the parent-child relationship as a mechanism by which family structure, instability, and parental conflict can affect child outcomes. Further, the patterns that are well established have been observed in western societies that began experiencing low levels of fertility and high levels of family dissolution and reconstitution, or a second demographic transition, 40 years ago (Lesthaeghe 2010). To our knowledge, no representative studies have observed the influence of the parent-child relationship independent of family structure, instability, and parental conflict in a low-divorce context like Korea where these demographic changes have begun to occur much more recently. It is possible that parent-child relationships are shaped in different ways by parental conflict in societies where such conflict has little chance of being resolved through marital dissolution. 


\section{Family Structure Change in Non-western Nations}

Examining family structure, parent-child relationship quality, and exposure to parental conflict in contexts where a second demographic transition is still in early stages can shed light on these questions. Research on family structure has predominantly focused on patterns and consequences of change in family structures in highincome, western nations (Park 2008). And yet, family structures in high-income, non-western countries not only exhibit different patterns and rates of change, but are doing so in different social, cultural, and historical contexts. Therefore, observing family structure in these different contexts allows us to examine the universality of findings, such as the importance of family structure for children's behavioral problems and the mechanisms by which family structure influences children.

Recent research examining family structures in high-income Asian nations where intense and rapid social and demographic transitions have occurred more recently (Park 2007, 2008, 2014; Chung and Emery 2010; Park and Raymo 2013), suggests that the impact of family structure on children can both follow patterns observed in western nations (Park 2008) and at times follow more regional patterns (Park and Raymo 2013). The few inquiries focusing on the effects of family structure and transition in these countries have largely examined educational outcomes; less is known about how rapidly changing family structures in Asian countries affect deviance and mental health issues. A single study of 454 Korean children found both similarities to and differences from western patterns of effects of parental divorce on child behavior problems (Chung and Emery 2010). One key difference was that unlike children in the United States, where divorce had the largest effect on their externalizing problems, the children in the Korean sample who had experienced divorce had significantly more internalizing, but not externalizing, problems than those in married families. While suggestive, these findings are not generalizable and do not include investigations of parental conflict or parent-child relations that might explain potential relationships between family structure and child behavior problems. These are especially salient mechanisms in a country like Korea where divorce has historically been much less common than in western countries, and is thus less likely to provide a possible stress relief for high-conflict families (Amato et al. 1995).

The Korean context is also one that experienced intense social change, as well as substantial economic and educational growth, in the latter half of the twentieth century. Such change may not only mean that divorce becomes more common as women become increasingly educated and able to compete in the labor market, but also that women may be able to use their income, employment, and education as protective factors against child behavior problems in the face of family dissolution. Yet cultural pressures to maintain traditional and "successful" families—or at least the facades of successful families - are still operative in non-western nations such as Korea, Taiwan, or Singapore. While cohabitation has become a common alternative to marriage in many western countries, the marginalization of cohabiting couples and infrequency of cohabitation in non-western countries (Yoo 2015; Raymo et al. 2015) has led to such reluctance in the reporting of cohabitation that the Korean government has not been able to obtain reliable statistics on cohabitation (Yoo 2015). And, even as the crude divorce 
rate in Korea began increasing in the 1990s to two divorces per 1000 (Lee 2006; Dommaraju and Jones 2011), traditional family values remain important, and the social stigma of divorce and normative sanctions against divorce in Korea remains especially high (Eun 2007; Chung and Emery 2010; Park and Raymo 2013). Not only is divorce less common, but when divorce occurs in Korea it is also more likely to occur in the second decade of marriage when Korean children are older (Lee 2006). As a result, parents may more often remain in high-conflict marriages when compared to parents in western countries. Under such circumstances, children in high-conflict, two-parent families may experience more adverse effects on their behavior than children whose parents have divorced or remarried (Jekielek 1998; Morrison and Coiro 1999), even as these non-traditional family forms remain relatively uncommon in the culture. While family relationship quality matters across contexts (Cox and Paley 1997), we suspect that these measures may be even more important in a context where instability is rare and, consequently, individuals in poor relationships are more likely to remain in those relationships. Therefore, children living with parents who have a low-quality relationship will be exposed to conflict on a much more regular basis.

\section{This Study}

Our study contributes to the literature in three major ways: (1) we test the influence of parent-child relationship quality, a rarely-tested mechanism through which family instability influences children, and examine the extent to which parent-child relationship quality accounts for the association between family structure and child behavior, (2) we consider the independent influence of parental conflict, parent-child relationship quality, and family structure on child well-being to assess their importance and their mediating roles, and (3) we examine child behavioral problems in Korea, a low-instability context where two-parent families predominate. Past research in western contexts (Amato and Keith 1991; Cherlin et al. 1991; Jekielek 1998; Morrison and Coiro 1999) suggests that with so little family instability, parental conflict may be especially impactful on children's behavioral problems. As a result, we expect parental conflict to negatively affect behavioral problems in Korean children. Also, with transitions being unusual in the Korean context and two- parent, married family structures so normative, we expect the impact of family structure transitions or living in a non-normative family structure to be associated with worse child behavioral problems even after controlling for parental conflict, parent-child relations, family resources, and selectivity factors. Finally, in the Korean context where family structure change is less common than in western nations, we expect the effects of family structure on child behavioral problems to be mediated by family relationship measures such as parent-child relations or parental conflict. 


\section{Data and Methods}

We use data from the Korea Youth Panel Survey (KYPS). KYPS is a longitudinal cohort study aimed at understanding the career development and deviant behaviors of adolescents in Korea. The survey applied a three-stage stratified sampling design-sampling from school districts, schools, and classes-to obtain a nationally representative sample. It includes two cohorts. The younger cohort, whom we examine here, were followed from fourth to eighth grade (2003-2008), creating five waves of data. Answers to survey questions were self-reported with the help of an interviewer (National Youth Policy Institute 2012).

The KYPS data are exceptionally well-suited for examining family structure, family dynamics, and the well-being of children. Most importantly, KYPS includes information regarding children's internalizing and externalizing behaviors, parent-child relationship quality, and parental conflict. This unique information allows us to explore the impact of relationship quality in a context with high family stability and low rates of divorce.

\section{Sample}

Participants were interviewed once a year for 5 years, totaling five waves of data. For our cross-sectional models, we include all participants who were in the sample at the fifth and final wave $(N=2448)$. Our longitudinal models include all participantwaves $(N=14,220$ participant-waves across $N=2844$ children). Most of the sampled children, $86 \%$, remained in the study for all five waves. Although there is no way to entirely avoid the effects of attrition, weighting is a commonly used strategy (Vandecasteele and Debels 2006). We employ weighting here (described below).

In order to more fully observe the effect of attrition, we compared children in the first wave of data (the "original" sample) to children that remained in the fifth and final wave (the analytic sample). Demographically, our analytical sample and the original sample had few differences. Most children resided in a two-parent, stable household (94.8\% in the analytic sample and $94.7 \%$ in the original sample). Further, the analytic and original samples were similar in the percentage of children who were female ( $46.8 \%$ in the analytic sample and $46.4 \%$ in the original sample), the average age (9.9 for both samples, $S D=0.4)$, and average number of siblings $(1.1$ for both samples, $S D=0.6$ ). Household monthly income was very similar across samples (around \$2700 in both samples) as well as mother's employment (around $50 \%$ employed full-time in both samples) and father's employment (around 96\% employed full-time in both samples). Finally, in both samples similar numbers of mothers had a high school education $(61 \%$ of the original sample and $63 \%$ of the analytic sample) or a college degree (25\% in the original sample and $22 \%$ in the analytic sample).

There were very little missing data overall. Among the participants who were in the sample at the fifth wave, some variables had no missing data (child age, and child gender), other variables had fewer than $5 \%$ of values missing (parental conflict, parent-child relationship quality, household monthly income, mother's education, 
and father's education), and three variables had fewer than $9 \%$ of values missing (respondent family structure, mother's employment and father's employment). In order to maintain the entire sample across models, we employed multiple imputation. Due to issues with multicollinearity, imputation was performed on indices rather than on items in the indices. Imputation of new data sets can be limitless; however, 20 iterations is an acceptable threshold (Johnson and Young 2011). We performed 25 iterations to ensure confidence in our results. We follow von Hippel (2007) in excluding cases on which the dependent variables (internalizing and externalizing) were imputed after the imputations were completed.

\section{Measures}

\section{Dependent Variables}

Our two dependent variables are internalizing and externalizing behaviors. We measure internalizing behaviors with a standardized index including the following items: "sometimes I feel extremely anxious with no apparent reason," "I worry about everything," "sometimes I think that I am a bad person," "sometimes I think that I am a worthless person," "sometimes I feel extremely lonely with no apparent reason," "sometimes I feel extremely sad and gloomy with no apparent reason," "I am not interested in anything," "I try to assuage my anger whenever I get angry," and "sometimes I feel suicidal with no apparent reason." Participants responded to these statements on a five-point Likert scale of "strongly disagree," "disagree," "neither disagree nor agree," "agree," and "strongly agree." Responses were averaged across all items and then standardized to ensure a mean of 0 and standard deviation of 1 . We use this index $(\alpha=0.82)$ as a continuous measure of general internalizing behavior problems. Values greater than zero indicate more internalizing behaviors while values less than zero indicate fewer internalizing behaviors.

We measure externalizing behaviors using this same process. The externalizing scale includes the following items: "I may hit other people when I feel annoyed," "I will hit back at a person who hits me," "I fight more frequently than others do," "sometimes I can't suppress an impulse to hit other people," "I am often seized by an impulse to throw an object whenever I get angry," and "I consider myself as an explosive soon to be blown off." Like the internalizing measure, we standardized the externalizing behavior problem index $(\alpha=0.86)$ and used it as a continuous measure of general externalizing behavior problems. Values greater than zero indicate more negative externalizing behaviors while values less than zero indicate fewer externalizing behaviors.

\section{Independent Variables}

Our key independent variables are family structure, parent-child relationship quality, and parental conflict. In each wave, we measure family structure by constructing three categories that reflect both the number of biological parents available to the child and the number of family transitions (i.e., instability) a child likely 
experienced: living with two biological parents, living with a single parent (either mother or father), and living in a two-parent family that includes a non-biological parent (generally created by a remarriage). We also measure instability by examining whether family structure has changed from the structure indicated in previous waves. Because of the low levels of instability and non-marital births in Korea (Statistics Korea 2018b), most children living with a single parent have experienced one transition, and children living in an unstable, two-parent household with a nonbiological parent most likely experienced two or more transitions. Due to small sample sizes in categories representing respondents living with a single father, we did not distinguish further based on gender of single parent (all included in the single-parent category). The unstable, non-biological two-parent family category also includes a very small number of cases where biological parents married during the survey years; however, almost all of the cases in the unstable two-parent family category represent a remarriage of a biological parent to a non-biological parent. We include family structure information from Wave 5 for cross-sectional models and from Waves $1-5$ in longitudinal models.

We also measure the relationship quality between the participants and their parents in each wave. We refer to this as parent-child relationship quality. This index includes the items "my parents and I have frequent conversations," "my parents and I candidly talk about everything," "my parents always treat me with love and affection," and "my parents and I try to spend much time together." Participants responded to these statements with a five-point Likert scale from "very untrue," coded as 1, to "very true," coded as 5. Responses to these items were averaged to create the relationship quality index $(\alpha=0.76)$, which was included as a continuous measure. A value of one indicates the lowest relationship quality and a value of five indicates the highest relationship quality.

Finally, we created a measure of parental conflict in each of the five waves. Past literature suggests that parents' relationship quality, often measured as the degree of conflict, has important implications for children's well-being and development (e.g., Margolin 1988, Fincham and Osborne 1993, Katz and Gottman 1993, Katz and Gottman 1994). To measure parental conflict, children were presented with the following statements and asked how true these statements were from "very untrue," coded as 1, to "very true," coded as 5: "I frequently see my parents badmouth or swear at each other" and "I frequently see one of my parents hit the other one." The responses to these questions were averaged to create an index $(\alpha=0.81)$, which was included as a continuous variable. While interparental conflict is ideally assessed using multiple measures from both parents and children, the two measures we used were the only parental conflict measures available in the KYPS data. We acknowledge that our two measures capture intense and relatively extreme forms of conflict; however, these types of conflict are more common in this context than in contexts like the United States (Ko and Park 2020; Park et al. 2017; Han et al. 2017; Kim et al. 2009). As a result, both the possibility that more extreme measures of conflict might be especially associated with child outcomes and the possibility that the presence of what westerners would consider extreme forms of conflict might have different associations with child outcomes in Korea exist. Therefore, examining this type of serious parental conflict and its relation to family structure and child well-being is 
useful and relevant. To distinguish the relative severity of the interparental conflict measures we have available here, we refer to this index as serious parental conflict throughout the rest of the paper. We include information on both parent-child relationship and serious parental conflict from Wave 5 for cross-sectional models and from Waves 1-5 in longitudinal models.

\section{Control Variables}

We also account for several factors that influence family structure, family dynamics, and internalizing and externalizing behaviors. First, we account for characteristics of the focal child. Due to past literature finding significant gender differences in both externalizing and internalizing behaviors (Leadbeater et al. 1999), we account for the child's sex ( 1 female, 0 male). We also include the child's age (in years) and number of siblings (a count variable). Second, we include characteristics of the household. We include household monthly income as a continuous measure in dollars. In light of findings suggesting that less-educated mothers across many settings are more likely to divorce (Park and Raymo 2013; Pew Research 2015; Dufur and Alexander 2017), and in order to examine the role of selectivity on family structure change and subsequent child behavioral problems, we account for both mothers' and fathers' education. Both are coded as categorical variables with the categories "less than a high school degree", "high school", "some college", and "college or higher." Finally, we measure both parents' employment status as a categorical variable that includes the categories "unemployed", "employed part-time", and "employed fulltime." With the exception of child gender, which was asked in Wave 1, we include information on each of these control variables from Wave 5 for cross-sectional models and from Waves 1-5 in longitudinal models. Maternal age at birth and family structure at birth are commonly controlled for as measures of selectivity when examining the impact of family structure on child outcomes; however, neither of these measures is available in the KYPS data. From Korean population data, we find that Korean average maternal age at first birth is 31.6 years old (Statistics Korea 2018a), the highest in the OECD (2016), but we cannot tell from the KYPS data whether single or remarried mothers might have given birth at younger ages. With regards to family structure at birth, unwed childbirth remains especially uncommon in Korea, as $98 \%$ of births in 2017 were to married parents (Statistics Korea 2018b), also the highest among OECD countries (OECD 2018b). This suggests that despite the lack of direct measures in our data, the vast majority of Korean children in our sample were born to married biological parents, with mothers who were older than most mothers in western nations.

Our data are not without limitations. We are not always able to untangle exactly whom respondents are referring to when they are asked about "parents." For example, when asked about paternal education, it is unclear if children in stepfamilies were referring to a stepfather or a non-residential biological father when answering. Respondents were asked to consider their parent in answering and then, if they did not live with a parent, a legal guardian. However, all children in the KYPS data lived with at least one biological parent. Similarly, in the parent-child relationship quality measure, we could not differentiate between how respondents feel about their mothers and fathers. A 
child could have a high-quality relationship with his or her mother but not with his or her father, a pattern that is indistinguishable in our data. Further, information on nonresident parents could be unavailable for children living in single-parent households, though we found many respondents in single-parent families provided information on both parents. To test this latter concern, we observed patterns in missing data. Although relatively few values were missing generally, children in single-parent families had higher levels of missing data on father's employment status (15-45\% across waves) than children in two-parent families (generally less than 10\%). In order to keep these children in the sample and utilize father's employment status as a control variable, we imputed this information as described above. We also estimated models without imputing data and models without including father's employment as a control (results available upon request). Both approaches garnered substantively similar results to the results presented here.

\section{Analytic Strategy}

To examine the relationships between family structure, relationship quality, and internalizing and externalizing behaviors, we first report descriptive statistics (Table 1). We then examine child behavioral problems cross-sectionally in the fifth and final wave of data (Table 2). For these models, other than gender, which is measured only in Wave 1, all variables were measured in the fifth wave of data. A cross-sectional approach allows us to focus on the context and circumstances the children are in at a particular moment and how various factors at this point in time may be associated with their behavioral problems. Due to the continuous nature of our dependent variables, we utilize ordinary least squares (OLS) regressions in our cross-sectional analysis. Next, we employ generalized estimating equation (GEE) models in order to utilize all five waves of data while still accounting for correlation among repeated or clustered measures (Zorn 2001). GEE models allow us to assess variability in our dependent variables and how this variability corresponds to our independent variables within individuals across time. This approach allows us to use information across all five waves of data, accounting for developmental differences as children age. Other than gender, which is measured only in Wave 1, each variable included in our models was measured at each wave of data and allowed to vary across time in the longitudinal models.

In each regression table, our first models include family structure, the primary independent variable, alone. The second models add parent-child relationship quality and our measure of serious parental conflict. Our final models include all the control variables. All models are weighted using survey weights (wave five survey weights for OLS models and wave one survey weights for GEE models). All models are estimated with robust standard errors. 
Table 1 Characteristics of children aged 13-15 (grade eight), means and percentages, Korea, 2008 $(N=2448)$

\begin{tabular}{|c|c|c|c|c|}
\hline & Mean or percent & Standard dev & Minimum & Maximum \\
\hline \multicolumn{5}{|l|}{ Family structure } \\
\hline Biological, two-parent, stable & $88.44 \%$ & & & \\
\hline Single parent & $6.68 \%$ & & & \\
\hline Non-biological/unstable two-parent & $4.88 \%$ & & & \\
\hline Parent-Child Relationship Index (total) ${ }^{\mathrm{a}}$ & 3.73 & 0.69 & 1.00 & 5.00 \\
\hline Often talk with parents & 3.61 & 0.96 & 1.00 & 5.00 \\
\hline Speak honestly with parents & 3.29 & 1.07 & 1.00 & 5.00 \\
\hline Feels loved by parents & 3.76 & 0.90 & 1.00 & 5.00 \\
\hline Spends time with parents & 3.47 & 0.93 & 1.00 & 5.00 \\
\hline Parental Conflict Index (total) ${ }^{\mathrm{a}}$ & 1.75 & 0.92 & 1.00 & 5.00 \\
\hline Parents do not fight often (verbally) & 1.92 & 1.07 & 1.00 & 5.00 \\
\hline One parent does not hit the other & 1.58 & 0.92 & 1.00 & 5.00 \\
\hline \multicolumn{5}{|l|}{ Child characteristics } \\
\hline Female & $46.77 \%$ & & & \\
\hline Age & 13.85 & 0.36 & 13.00 & 15.00 \\
\hline Number of siblings & 1.15 & 0.58 & 0.00 & 5.00 \\
\hline \multicolumn{5}{|l|}{ Household characteristics } \\
\hline Household monthly income & 3117.88 & 1637.51 & 0.00 & $27,000.00$ \\
\hline \multicolumn{5}{|l|}{ Mother's education } \\
\hline Less than high school & $7.18 \%$ & & & \\
\hline High school & $62.96 \%$ & & & \\
\hline Some college & $8.12 \%$ & & & \\
\hline College or higher & $21.75 \%$ & & & \\
\hline \multicolumn{5}{|l|}{ Father's education } \\
\hline Less than high school & $5.95 \%$ & & & \\
\hline High school & $44.83 \%$ & & & \\
\hline Some college & $10.08 \%$ & & & \\
\hline College or higher & $39.13 \%$ & & & \\
\hline \multicolumn{5}{|l|}{ Mother's employment } \\
\hline Full time & $48.92 \%$ & & & \\
\hline Part time & $6.11 \%$ & & & \\
\hline Unemployed & $44.97 \%$ & & & \\
\hline \multicolumn{5}{|l|}{ Father's employment } \\
\hline Full-time & $95.04 \%$ & & & \\
\hline Part-time & $1.45 \%$ & & & \\
\hline Unemployed & $3.51 \%$ & & & \\
\hline
\end{tabular}

Data: Korean Youth Panel Survey, Cohort 2, Wave 5 


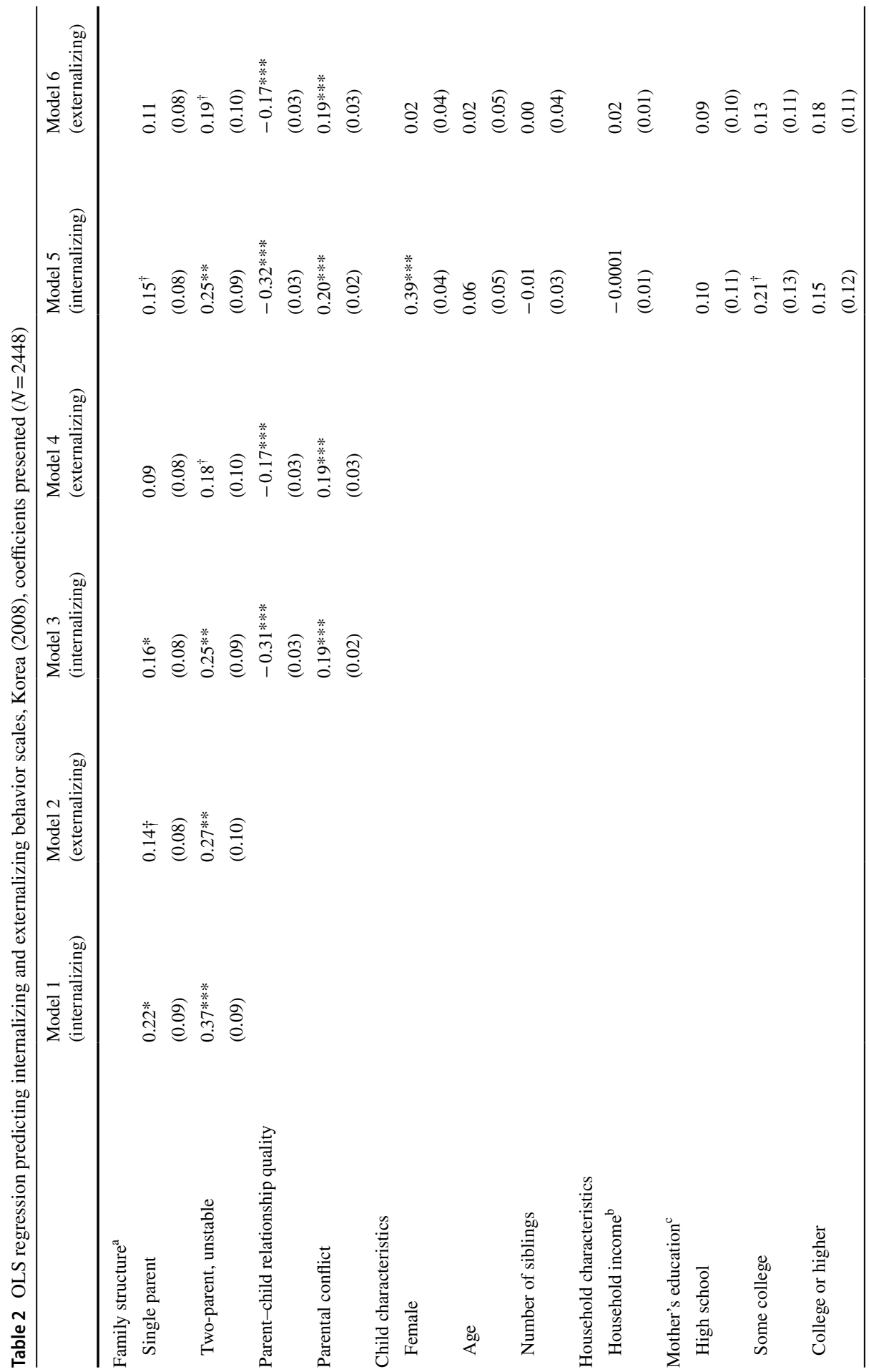




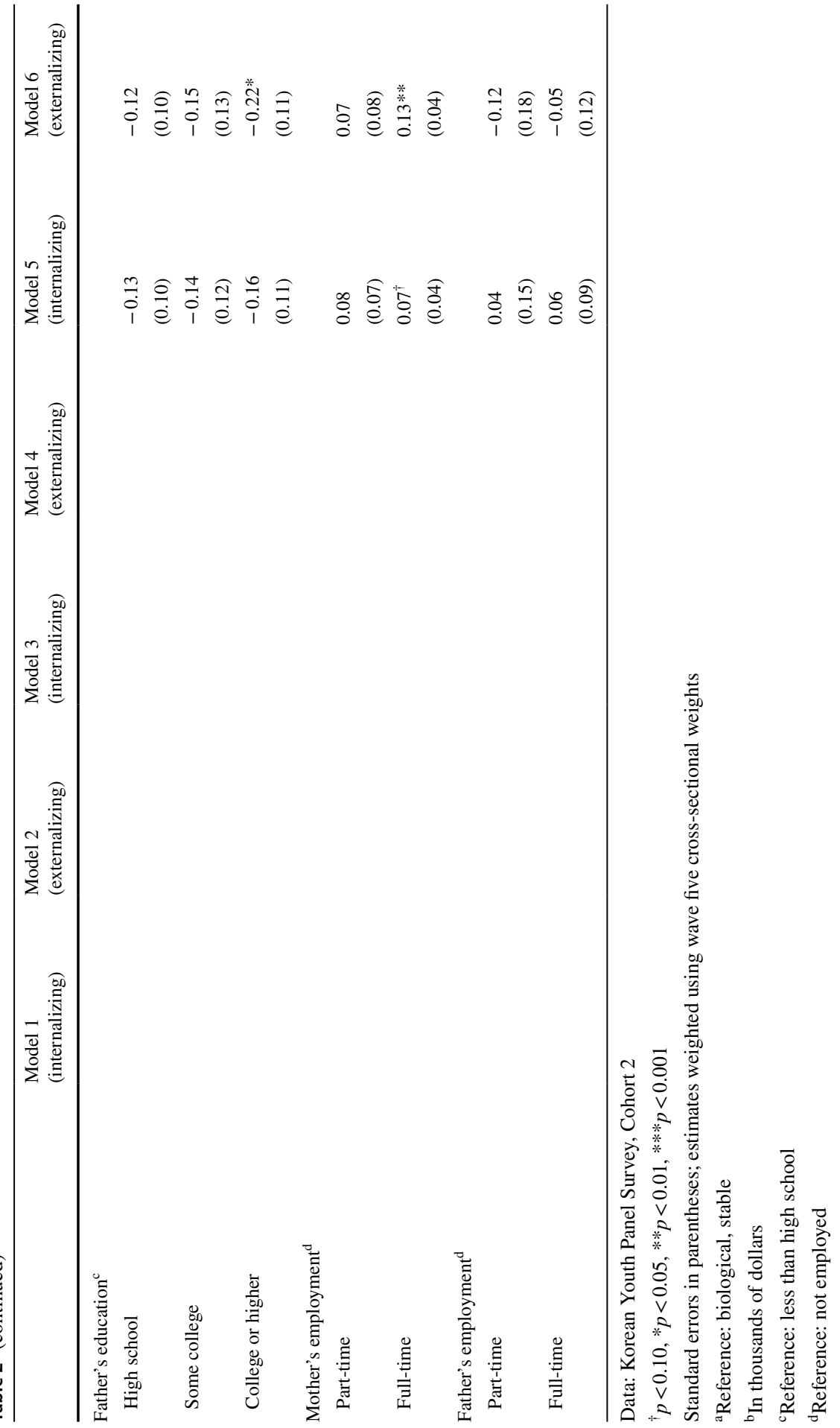




\section{Results}

Approximately $88 \%$ of our sample are living with their biological mother and father who are married. Substantially fewer children live with a single-parent $(6.7 \%)$ or in an unstable, two-parent family (4.9\%) (see Table 1). These family patterns, signaling high levels of stability, are consistent with past literature on Korea (Park 2008) and demonstrate how different the Korean context is from western contexts where children's family instability is higher on average. Because of this low instability and, consequently, low variation in family structure, parent-child relationship quality and serious parental conflict indices may become increasingly important characteristics. Using these indices, we find that children, on average, report relatively high relationship quality with their parents (an average of 3.7 with a maximum of $5.0, S D=0.7$ ) and low levels of serious parental conflict (an average of $1.8, S D=0.9$ ). We do not present means and standard deviations from the externalizing and internalizing indices in Table 1 because they are standardized indices, each with a mean of 0 and standard deviation of 1 .

Turning to child characteristics, almost half of our sample is female (47\%). The respondents are 14 years old on average $(S D=0.4)$ and have one sibling $(S D=0.6)$. In terms of household characteristics, the average household monthly income is USD 3,117.88 with a fairly wide distribution. Korea is widely known for its highly educated population (OECD 2018c) and strict gendered norms (Eun 2007). This is reflected in our data. In our sample, very few parents have not graduated from high school (7\% of mothers and $6 \%$ of fathers), while about one-third of mothers and half of fathers have at least some college education or higher. Further, while only $49 \%$ of mothers report working full-time, almost all fathers $(95 \%)$ are working full-time.

Findings from our cross-sectional OLS models show that family structure and relationship quality are independently and significantly associated with children's behavior issues (see Table 2). Models 1 and 2 show results for internalizing and externalizing behaviors, respectively, using only family structure as an independent variable. Children living in single-parent families experience significantly more internalizing $(b=0.22, p<0.05)$ and externalizing behaviors $(b=0.14$, $p<0.10$ ) than children living in two-parent, stable families, though the coefficient is marginally significant for externalizing behavior problems. Similarly, children living in two-parent, unstable families report significantly more internalizing $(b=0.37, p<0.001)$ and externalizing $(b=0.27, p<0.01)$ behaviors than children living in two-parent, stable families. The coefficients for two-parent, unstable families are much larger than for single-parent families (over 1.5 times larger for internalizing and almost twice as large for externalizing), suggesting that greater exposure to instability is detrimental to child behavior.

After introducing parent-child relationship quality and serious parental conflict, family structure remains significantly associated with children's internalizing and externalizing behaviors (see Table 2, Models 3 and 4). Children living with a single parent experience 0.16 of a standard deviation more internalizing behaviors than children living with two biological parents, and this finding 
is statistically significant $(p<0.05)$. Similarly, children living in a two-parent, unstable household experience a fourth of a standard deviation $(b=0.25)$ more internalizing behaviors than children living with two biological parents, and this finding is statistically significant $(p<0.01)$.

In Models 3 and 4, parent-child relationship quality is also significantly and negatively related to both internalizing $(b=-0.31, p<0.001)$ and externalizing $(b=-0.17, p<0.001)$ behaviors. That is, children who report higher-quality relationships with their parents experience fewer internalizing and externalizing behaviors. Like parent-child relationship quality, serious parental conflict is also significantly related to children's internalizing and externalizing behaviors. Children who report higher levels of serious parental conflict report significantly more internalizing $(b=0.19, p<0.001)$ and externalizing $(b=0.19, p<0.001)$ behaviors than children who report lower levels of parental conflict. These coefficients remain similar in size and significance accounting for child and household characteristics (Table 2, Models 5 and 6).

To further explore whether relationship quality and serious parental conflict might explain the effects of family structure on child outcomes, we estimated formal mediation tests across all 25 multiply imputed iterations of our data (xtsgmediate in Stata 15) (results available upon request). We found that in the OLS cross-sectional models, parent-child relationships did not significantly mediate the relationship between family structure and child internalizing and externalizing behavioral problems, and evidence of serious parental conflict mediating these effects was weak and inconsistent across iterations. This suggests that while parent-child relationship and serious parental conflict are useful predictors of child behavior problems, family structure exerts an effect independently of the ways it may affect relationships between parents and between parents and children.

Few of our control variables are significantly related to internalizing or externalizing behaviors. As found in prior studies, girls report significantly more internalizing behaviors than boys $(b=0.39, p<0.001)$ (e.g., Leadbeater et al. 1999). Further, children whose mothers work full-time experience significantly more internalizing $(b=0.07, p<0.10)$ and externalizing behaviors $(b=0.13, p<0.01)$ compared to children whose mothers do not work, albeit, the findings for internalizing behaviors are only marginally significant. Considering Korea's unusually large gender wage and employment gaps (OECD 2017), mothers full-time work is still considered nonnormative and likely reflective of economic disadvantage.

To ensure confidence in our results, as well as to fully utilize all of the data available in KYPS, we further tested these relationships using longitudinal models. Unlike OLS models, GEE models allow for examinations of observations over time with observations clustered within individuals. Longitudinal data such as KYPS include repeated measures of behavior problems, relationships, and other key variables as respondents age across the survey waves. These data allow us to better account for important differences as children develop, such as respondent maturation. We use GEE models to better account for unobserved heterogeneity and correlation between repeated measurements within individual children.

Results from the GEE models largely support the conclusions from the OLS models (see Table 3): family structure, parent-child quality, and serious parental 


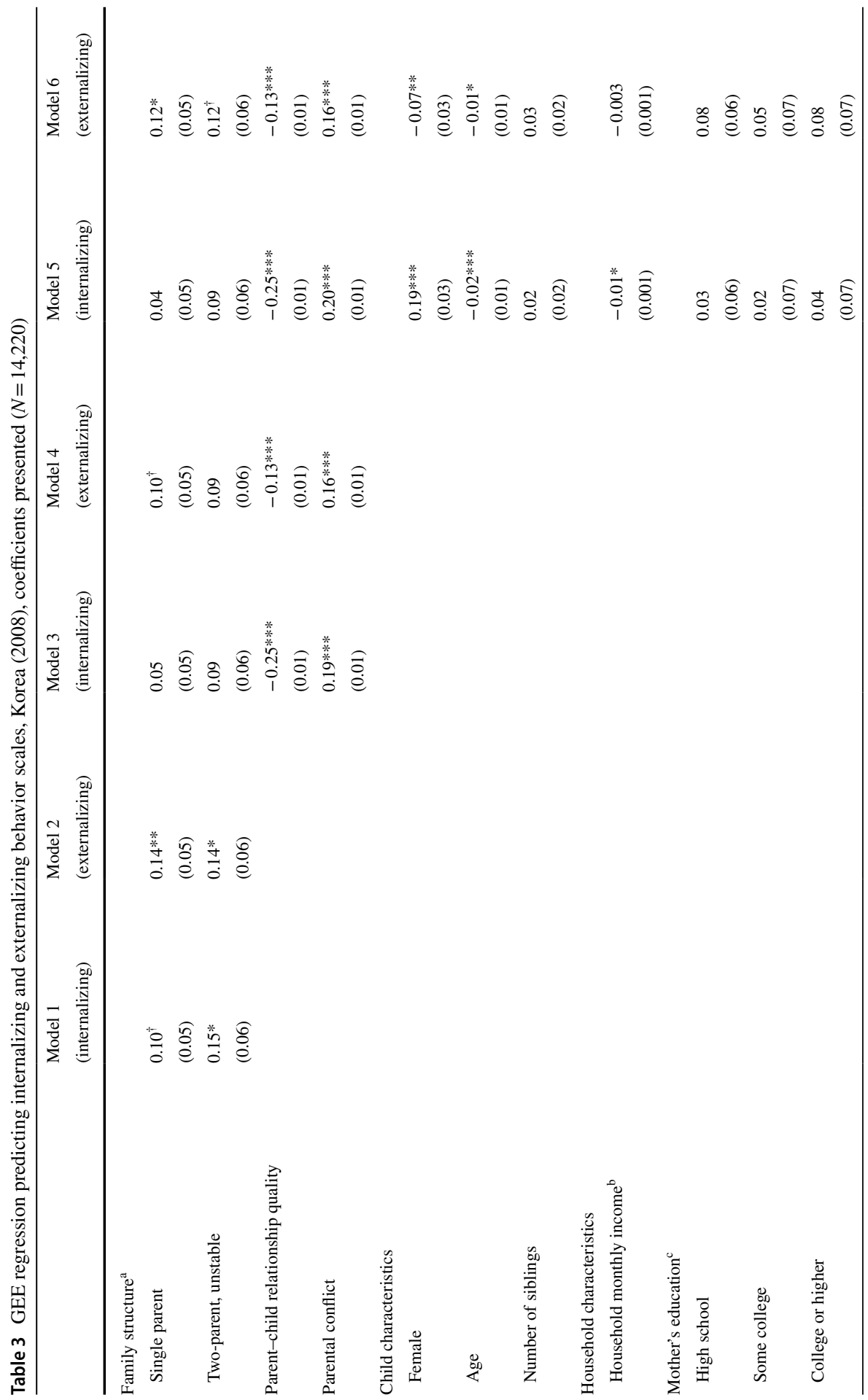



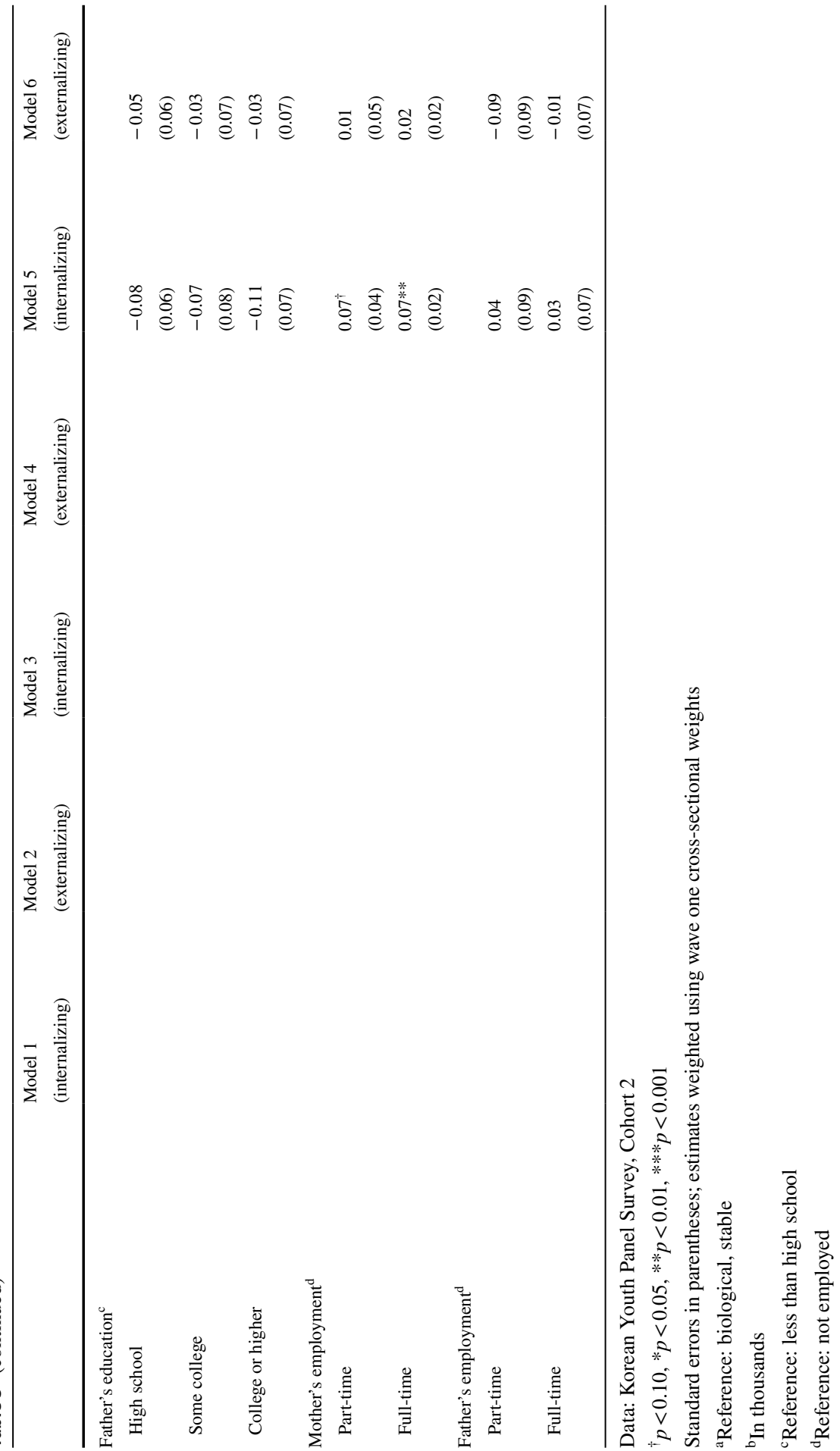
conflict independently and significantly relate to children's internalizing and externalizing behaviors. In Models 1 and 2, the results show that children living in single-parent families experience more internalizing behaviors $(b=0.10, p<0.10)$ and significantly more externalizing behaviors $(b=0.14, p<0.05)$ than children living in two-parent, stable families. Similarly, children living in two-parent, unstable families experience significantly more internalizing $(b=0.15, p<0.05)$ and externalizing behaviors $(b=0.14, p<0.05)$.

After introducing parent-child relationship quality and serious parental conflict (see Table 3, Models 3 and 4), living in a single-parent family is no longer significantly related to higher levels of internalizing behaviors $(b=0.05)$ and only marginally related to externalizing behaviors $(b=0.10, p<0.10)$. Further, living in a two-parent, unstable family is also no longer significantly related to internalizing or externalizing behaviors. One possible explanation for the lack of significance is the absence of variability in family structure and instability across waves. Longitudinal tests of within-person variation in behavior problems are stricter, more conservative tests, explaining variation in variables that reflect narrower distributions than the cross-sectional tests we report above. Alternatively, however, it is possible that parent-child relationship quality explained variation in this relationship. Using a formal mediation test with the xtsgmediate program in Stata 15, we found that parent-child relationship quality significantly mediated the relationship between family structure and internalizing and externalizing behaviors in the GEE models. However, we found no evidence that serious parental conflict significantly mediated this relationship.

Mirroring the findings in OLS models, parent-child relationship quality and serious parental conflict are significantly related to children's internalizing and externalizing behaviors (Models 3 and 4). Children who report higher-quality relationships with their parents experience significantly fewer internalizing $(b=-0.25, p<0.001)$ and externalizing behaviors $(b=-0.13, p<0.001)$ than children who report lowerquality relationships with their parents. Substantively similar findings emerge for serious parental conflict. Children who report higher levels of serious parental conflict experience significantly more internalizing $(b=0.19, p<0.001)$ and externalizing behaviors $(b=0.16, p<0.001)$ than children who report lower levels of serious parental conflict. These relationships remain significant after accounting for child and household characteristics (see Table 3, Models 5 and 6).

In the full GEE models, several child and household variables are significantly related to internalizing and externalizing behaviors. Similar to the cross-sectional OLS models, female children experience significantly higher increases in internalizing $(b=0.19, p<0.001)$ and significantly lower increases in externalizing behaviors $(b=-0.07, p<0.01)$ than boys, matching past research (Leadbeater et al. 1999). Older children experience significantly fewer internalizing $(b=-0.02, p<0.001)$ and externalizing behaviors $(b=-0.01, p<0.05)$ than younger children. Increases in household monthly income are negatively and significantly related to internalizing behaviors $(b=-0.01$ in thousands, $p<0.05)$. And children whose mothers are employed full-time experience significantly more internalizing behaviors $(b=0.07$, $p<0.01)$ than children whose mothers are not employed. 


\section{Sensitivity Analyses}

We estimated our models under a number of additional specifications to ensure our findings were not statistical artifacts, especially since we use data that has a relatively small proportion of children in non-traditional family structures: (1) we used the number of family transitions a child had experienced during the survey period as our primary independent variable instead of family structure, (2) we estimated our models under before imputing missing data and compared them to post-imputation results, and (3) because our parent-child relationship quality measures were ambiguous in asking about parents in general, rather than specifying which parent, we stratified models by family structure; in these stratified models, family structure was excluded as an independent variable.

Results across these specifications (available upon request) were very similar to the results we present here. Across all models, children living in unstable two-parent families, or in families who had experienced two or more transitions, experienced more internalizing and externalizing behaviors than children living with two biological parents, independent of parent-child relationship quality and serious parental conflict. This finding was significant in every model except when estimating the number of family transitions using a GEE model; however, that result is also in line with the way family structure is no longer significant in the full GEE models reported above, again providing reassurance that those findings are not statistical artifacts. Estimating the number of family transitions as the primary independent variable using the OLS models garnered similar significant results to the models we report above. Further, findings for parent-child relationship quality and serious parental conflict remained significant and in the expected directions across children in all family structures. Overall, then, our sensitivity tests suggest that we can be confident in our key findings: Korean children who live in non-traditional family structures or who transition into those structures, who experience serious interparental conflict in their homes regardless of family structure, or who have worse relationships with their parents experience more behavior problems and increasing behavior problems over time.

\section{Discussion}

In this study, we make three important contributions. First, we examine a relatively neglected mechanism through which family change may affect children: parent-child relationship quality. Second, we examine the independent influence of family structure and instability, parent-child relationship quality, and parental conflict on child outcomes. And third, we use data from Korean families to examine the universality of research related to family structure in a high income, non-western context that has more recently experienced a second demographic transition.

We find several notable results. As expected, we find that Korean families in our study were much less likely to experience marital disruption than families 
in high-income, western nations. And yet, despite this comparative stability in family structure, we see that family structure is meaningful for Korean children. Being in a stable, married, two biological parent family generally led to fewer behavioral problems among Korean children, even after accounting for both family relationship quality and a wide range of demographic variables.

We also included mechanisms through which family structure may be affecting children's behavior. We find that lack of exposure to serious parental conflict, as well as positive parent-child relations lead to fewer behavioral problems in Korean children, net of each other. These mechanisms are important to this analysis because of the low levels of divorce in general in Korea, and the unusual tendency for Koreans to divorce in the second decade of marriage when children are older (Lee 2006). As a result, Korean children in the age range we examined are much more likely to be in a family where married parents may have conflict without the possible resolution provided by a divorce.

Serious forms of parental conflict have a significant impact on children's internalizing and externalizing behavioral problems, even when controlling for family resources, parental characteristics, and family structure. Korean children have fewer problems when their parents fight less. Still, our models generally suggest that experiencing family transitions is problematic for Korean children net of serious parental conflict. These results support findings from research on western families where both family structure change and parental conflict affected children's behavior problems (Jekielek 1998; Riggio 2004; Yu et al. 2010), strengthening claims for the universality of such patterns.

We find similar results when examining the impact of parent-child relations on Korean children's problem behaviors. Positive parent-child relations have a protective effect against behavior problems in Korean children, even when controlling for conventional explanations such as depleted resources or parental characteristics. Further, we found some evidence that parent-child relations significantly mediated the relationship between family structure and child well-being, validating its importance. However, even amidst this mediation, family structure remained significant. Therefore, our results support the notion that family structure and family dynamics are important correlates for child well-being.

These findings suggest that more efforts should be made to target the health of Korean children in all non-traditional families, but particularly children in blended families, as the process of separating adults from and adding adults to children's lives is associated with behavioral problems. In a nation like Korea where the vast majority of children are raised in two-parent married families, marriage norms are powerful and intact, and two-parent families are held in high regard. And yet, as the number of divorces in Korea has increased, so too has the number of remarriages (Statistics Korea 2013). As we see from this research, the remarriage process can be detrimental to the children experiencing these changes, perhaps because these family transitions are still culturally viewed as non-normative. Social programs targeting children and parents considering remarriage may prove especially beneficial.

One potential pathway to aid parents and children in such circumstances is programs that would facilitate positive parent-child relationships. While the effects of positive parent-child relationships did not completely overcome the detrimental 
effects of family structure change, we found that such positive intrafamilial dynamics did reduce Korean children's behavioral problems, even for children in non-traditional family situations. Because of the high-stress and intense educational system in Korea, school-aged children spend much of their time in various forms of educational training, and not with their families. Therefore, programs emphasizing the importance of spending time together and helping to facilitate parent-child relationships through activities like frequent and candid conversations may help children navigate family structure change more successfully. Lastly, when children perceived low levels of serious parental discord, they were much less likely to report behavioral problems. Helping parents in all family structures navigate their own relationships and reduce serious conflict could help their children's emotional well-being and behavior.

Finally, this research captures the impact of family structure on children's behavior and the mechanisms through which family structure may be affecting children's behavior in a high-income, non-western nation that is still in the earlier stages of a second demographic transition. This means that these results are capturing change in important social behaviors and the ramifications of these behaviors (in this case, child behavioral problems) in a context at the cusp of more dramatic social changes. Based on what western nations experienced decades ago, this may lead to further normalization of the experiences of being in a non-traditional family structure or experiencing family structure change; on the other hand, we may see the emergence of uniquely Asian or Korean versions of this change where historical and cultural influences continue to stigmatize non-traditional family structures or mitigate the trend of cohabitation before or instead of marriage.

This study was subject to several limitations. First, the data do not include information about family structure at birth, instead beginning in the fourth grade of elementary school. This prevents an examination of important factors that may occur before children are in school and are more dependent on their parents. In a society only beginning to experience the second demographic transition, family structure changes in the "tender years" (Amato and Anthony 2014) of early childhood may exert stronger or longer lasting negative effects on children. This also limits our ability to test whether there are associations between child outcomes and the amount of time spent in particular family structures. Second, our parent-child quality measures are somewhat ambiguous as the questions used do not specify which parent the child is reporting about (the questions simply refer to "parents"). This limits the conclusions we can make about specific parents (e.g., fathers versus mothers, stepparents, etc.). In order to test the robustness of this finding, we estimated models stratified by union status, rather than including family structure as an independent variable, to assess whether findings were stronger for children in households with both biological parents, who experienced less ambiguity around this question. We found that parent-child relationship quality and serious parental conflict were significantly related to internalizing and externalizing behaviors, in the expected directions, across all family structures. Therefore, despite this ambiguity, children's perceptions of their relationship with their parents, however they may define them, are important for their well-being. Finally, measures of parental conflict in this data are limited to two items and represent severe behaviors, perhaps capturing some elements 
of abusive relationships. While abusive behavior can be part of parental conflict, conflating arguments or discordance with abuse is problematic. To our knowledge, these are the best data to address both parental conflict variables and a context in which divorce is still relatively uncommon, but data with more nuanced measures of parental conflict could help examine the degree to which common forms of conflict both influence child behavior and explain potential effects of family structure or transitions.

Overall, our results provide a compelling new direction for future research. More studies should incorporate measures of parent-child relationship quality, as it influences child well-being above and beyond both parental conflict and family structure. Reasons for why this happens could be explored more fully. Further, while we found that family structure, serious parental conflict and parental-child relationship quality had independent impacts on child behavioral problems, parent-child relationships may be an important mechanism through which family structure affects child behavior. These patterns represent both similarities and differences between the highincome, non-western context we study here and the western contexts upon which the bulk of the family literature is based. Instead of conceptualizing parent-child relationship quality as a mechanism explaining away the effects of family context, more research is needed to explore this concept as both an independent influence on children across family structures, and a way that family structure change affects child outcomes.

Acknowledgements We want to acknowledge the contributions of John Hoffmann, Alyssa Alexander, Carolina Otero, and Can Cheng from Brigham Young University. This research was supported by funding from the Eunice Kennedy Shriver National Institute of Child Health and Human Development (NICHD) to the Population Research Institute at The Pennsylvania State University for Population Research Infrastructure (P2C HD041025) and Family Demography Training (T32 HD007514).

\section{Compliance with Ethical Standards}

Conflict of interest The authors declare that they have no conflicts of interest.

\section{References}

Amato, P. R., \& Keith, B. (1991). Parental divorce and the well-being of children: A meta-analysis. Psychological Bulletin, 110(1), 26-46.

Amato, P. R., \& Booth, A. (1996). A prospective study of divorce and parent-child relationships. Journal of Marriage and the Family, 58(2), 356-365.

Amato, P. R., Loomis, L. S., \& Booth, A. (1995). Parental divorce, marital conflict, and offspring wellbeing during early adulthood. Social Forces, 73(3), 895-915.

Amato, P. R., \& Anthony, C. J. (2014). Estimating the effects of parental divorce and death with fixed effects models. Journal of Marriage and Family, 76(2), 370-386.

Aquilino, W. S. (2006). The noncustodial father-child relationship from adolescence into young adulthood. Journal of Marriage and Family, 68(4), 928-946.

Bachman, H. J., Coley, R. L., \& Carrano, J. (2011). Maternal relationship instability influences on children's emotional and behavioral functioning in low-income families. Journal of Abnormal Child Psychology, 39(8), 1149-1161.

Booth, A., \& Amato, P. R. (2001). Parental predivorce relations and offspring postdivorce well-being. Journal of Marriage and Family, 63(1), 197-212. 
Braithwaite, S., Steele, E., Spjut, K., \& Dowdle, K. K. (2015). Parent-child connectedness mediates the association between marital conflict and children's internalizing/externalizing outcomes. Journal of Child Family Studies, 24(12), 3690-3699.

Brown, S. L. (2010). Marriage and child well-being: Research and policy perspectives. Journal of Marriage and Family, 72, 1059-1077.

Carballo, J., García-Nieto, R., Álvarez-García, R., Caro-Cañizares, I., López-Castromán, J., Muñoz-Lorenzo, L., et al. (2013). Sibship size, birth order, family structure and childhood mental disorders. Social Psychiatry \& Psychiatric Epidemiology, 48(8), 1327-1333.

Chen, M., \& Yip, P. S. F. (2018). Decomposing the crude divorce rate in five countries: Singapore, Taiwan, South Korea, the UK, and Australia. Asian Population Studies, 2, 137-152.

Cherlin, A. J., Furstenberg, F. F., Jr., Chase-Linsdale, P. L., Kiernan, K. E., Robins, P. K., Morrison, D. R., et al. (1991). Longitudinal studies of effects of divorce on children in great Britain and the United States. Science, 252(5011), 1386-1389.

Chung, Y., \& Emery, R. (2010). Early adolescents and divorce in South Korea: Risk, resilience and pain. Journal of Contemporary Family Studies, 41(5), 855-870.

Cox, M. J., \& Paley, B. (1997). Families as systems. Annual Review of Psychology, 48(1), 243-267.

Creighton, M. J., Park, H., \& Teruel, G. M. (2009). The role of migration and single motherhood in upper secondary education in Mexico. Journal of Marriage and Family, 71(5), 1325-1339.

Cummings, E. M., Zahn-Waxler, C., \& Radke-Yarrow, M. (1981). Young children's responses to expressions of anger and affection by others in the family. Child Development, 52(4), 1274-1282.

Cummings, E. M. (1987). Coping with background anger in early childhood. Child Development, 58(4), 976-984.

Dommaraju, P., \& Jones, G. (2011). Divorce Trends in Asia. Asian Journal of Social Science, 39(6), $725-750$.

Dufur, M. J., \& Alexander, A. (2017). Does childhood family structure help create stratification in adult education and labor market attainment? An argument for the selectivity perspective. Sociology Compass, 11(1), 1-13.

Erel, O., \& Burman, B. (1995). Interrelatedness of marital relations and parent-child relations: A metaanalytic review. Psychological Bulletin, 118(1), 108-132.

Eun, K. S. (2007) Family values in Korea: A comparative analysis. In Paper presented at the 2007 World Family Policy Forum, Brigham Young University, Provo, UT.

Fincham, F. D., \& Osborne, L. N. (1993). Marital conflict and children: retrospect and prospect. Clinical Psychology Review, 13(1), 75-88.

Fomby, P., \& Cherlin, A. J. (2007). Family instability and child well-being. American Sociological Review, 72(2), 181-204.

Gorman, G. H., Eide, M., \& Hisle-Gorman, E. (2010). Wartime military deployment and increased pediatric mental and behavioral health complaints. Pediatrics, 126(6), 1058-1066.

Han, Y. R., Jeong, G. H., \& Kim, S. (2017). Factors influencing beliefs about intimate partner violence among adults in South Korea. Public Health Nursing, 34, 412-421.

Hoffmann, J. P. (2002). The community context of family structure and adolescent drug use. Journal of Marriage and Family, 64(2), 314-330.

Hoffmann, J. P. (2017). Family structure and adolescent substance use: An international perspective. Substance Use and Misuse, 52(13), 1667-1683.

Jekielek, S. M. (1998). Parental conflict, marital disruption and children's emotional well-being. Social Forces, 76(3), 905-936.

Johnson, D. R., \& Young, R. (2011). Toward best practices in analyzing datasets with missing data: Comparisons and recommendations. Journal of Marriage and Family, 73(5), 926-945.

Katz, L. F., \& Gottman, J. M. (1993). Patterns of marital conflict predict children's internalizing and externalizing behaviors. Developmental Psychology, 29(6), 940-950.

Katz, L. F., \& Gottman, J. M. (1994). Patterns of marital interaction and children's emotional development. In R. D. Parke \& S. G. Kellam (Eds.), Family research consortium: Advances in family research. Exploring family relationships with other social contexts (pp. 49-74). Hillsdale, NJ: Lawrence Erlbaum Associates Inc.

Kim, H. S. (2011). Consequences of parental divorce for child development. American Sociological Review, 76(3), 486-511.

Kim, J., Park, S., \& Emery, C. R. (2009). The incidence and impact of family violence on mental health among South Korean women: Results of a national survey. Journal of Family Violence, 24, 193. 
Ko, Y., \& Park, S. (2020). Building a new intimate relationship after experiencing intimate partner violence in victim-SURVIVORS of South Korea. Journal of Interpersonal Violence, 35(1-2), 3-24. https://doi.org/10.1177/0886260518814265.

Kouros, C. D., Papp, L. M., Goeke-Morey, M. C., \& Cummings, E. M. (2014). Spillover between marital quality and parent-child relationship quality: Parental depressive symptoms as moderators. Journal of Family Psychology, 28(3), 315-325.

Leadbeater, B. J., Kuperminc, G. P., Blatt, S. J., \& Hertzog, C. (1999). A multivariate model of gender differences in adolescents' internalizing and externalizing problems. Developmental Psychology, 35(5), 1268-1282.

Lee, Y. J. (2006). Risk factors in the rapidly rising incidence of divorce in Korea. Asian Population Studies, 2(2), 113-131.

Lee, D., \& McLanahan, S. S. (2015). Family structure transitions and child development: Instability, selection, and population heterogeneity. American Sociological Review, 80(4), 738-763.

Lesthaeghe, R. (2010). The unfolding story of the second demographic transition. Population and Development Review, 36(2), 211-251.

Margolin, G. (1988). Marital conflict is not marital conflict is not marital conflict. In R. D. Peters \& R. J. McMahon (Eds.), Social learning and systems approaches to marriage and the family (pp. 193-216). Philadelphia, PA: Brunner/Mazel.

McCulloch, A., Wiggins, R. D., Joshi, H. E., \& Sachdev, D. (2000). Internalising and externalising children's behaviour problems in Britain and the US: Relationships to family resources. Children \& Society, 14(5), 368-383.

McLanahan, S. S., \& Sandefur, G. (1994). Growing up with a single parent: What hurts, what helps. Cambridge, MA: Harvard University Press.

Morrison, D. R., \& Coiro, M. J. (1999). Parental conflict and marital disruption: Do children benefit when high-conflict marriages are dissolved? Journal of Marriage and Family, 61(3), 626-637.

National Youth Policy Institute. (2012). Korea Youth Panel Survey- Elementary 4th gradeUser's guide. Seoul, South Korea: National Youth Policy Institute

OECD. (2016). SF2.3.B: Mean age of women at first birth, 1995 and 2016 or latest available. OECD Family Database. Retrieved July 25, 2019 from https://www.oecd.org/els/soc/SF_2_3_Age_mothe rs_childbirth.pdf.

OECD. (2017). How does Korea compare? The Pursuit of gender equality: An uphill battle. Paris: OECD Publishing. https://doi.org/10.1787/9789264281318-en

OECD. (2018a). SF3.1: Marriage and divorce rates. OECD Family Database. Retrieved July 20, 2019 from https://www.oecd.org/els/family/SF_3_1_Marriage_and_divorce_rates.pdf.

OECD. (2018b). SF2.4.A: Share of births outside of marriage: Proportion (\%) of all births where the mother's marital status at the time of birth is other than married, 2016. OECD Family Database. Retrieved July 26, 2019 form https://www.oecd.org/els/family/SF_2_4_Share_births_outside_marri age.pdf.

OECD. (2018c). Population with tertiary education (indicator). Retrieved January 15, 2020 from https:// data.oecd.org/eduatt/population-with-tertiary-education.htm.

Park, H. (2007). Single parenthood and children's reading performance in Asia. Journal of Marriage and Family, 69(3), 863-877.

Park, H. (2008). Effects of single parenthood on educational aspiration and student disengagement in Korea. Demographic Research, 18(13), 377-408.

Park, H., \& Raymo, J. (2013). Divorce in Korea: trends and educational differentials. Journal of Marriage and Family, 75(1), 110-126.

Park, H. (2014). Single parenthood and children's education in Republic of Korea: An update. In H. Park \& K.-K. Kim (Eds.), Korean education in changing economic and demographic 153 contexts, education in the Asia-Pacific region: Issues, concerns and prospects (Vol. 23). Dordrecht: Springer. https://doi.org/10.1007/978-981-4451-27-7_9

Park, G. R., Park, E. J., Jun, J., \& Kim, N. S. (2017). Association between intimate partner violence and mental health among Korean married women. Public Health, 152, 86-94.

Pew Research Center. (2015). The link between a college education and a lasting marriage. Retrieved November 13, 2018 from https://pewrsr.ch/11f7xu9.

Pribesh, S., \& Downey, D. B. (1999). Why are residential and school moves associated with poor school performance? Demography, 36(4), 5212-5534.

Raymo, J. M., Park, H., Xie, Y., \& Yeung, W.-J. J. (2015). Marriage and family in East Asia: Continuity and change. Annual Review of Sociology, 41, 471-492. 
Riggio, H. R. (2004). Parental marital conflict and divorce, parent-child relationships, social support, and relationship anxiety in young adulthood. Personal Relationships, 11(1), 99-114.

Statistics Korea. (2013). Status of divorces and remarriages for the past three decades. Marriage and divorce. Retrieved August 5, 2019 from https://kostat.go.kr/portal/eng/pressReleases/8/11/index .board?bmode $=$ download $\& b S e q=\& a S e q=311954 \&$ ord $=1$.

Statistics Korea. (2018a). Mean age of mother by birth order for provinces. Statistical database, vital statistics. Retrieved August 15, 2019 from https://kosis.kr/eng/statisticsList/statisticsListIndex. do?menuId=M_01_01\&vwcd=MT_ETITLE\&parmTabId=M_01_01\&statId=1962004\&thema Id=\#SelectStatsBoxDiv.

Statistics Korea. (2018b). Live births by marital legitimacy for provinces, annual 1981-2017. Statistical database, vital statistics. Retrieved August 5, 2019 from https://kosis.kr/eng/statisticsList/stati sticsListIndex.do?menuId=M_01_01\&vwcd=MT_ETITLE\&parmTabId=M_01_01\&statId=19620 04\&themaId=\#SelectStatsBoxDiv.

Thomson, E., \& McLanahan, S. S. (2012). Reflections on "family structure and child well-being: economic resources vs. parental socialization". Social Forces, 91(1), 45-53.

Vandecasteele, L., \& Debels, A. (2006). Attrition in panel data: The effectiveness of weighting. European Sociological Review, 23(1), 81-97.

von Hippel, P. T. (2007). Regression with missing Ys: An improved strategy for analyzing multiply imputed data. Sociological Methodology, 37(1), 83-117.

Waldfogel, J., Craigie, T., \& Brooks-Gunn, J. (2010). Fragile families and child wellbeing. Future of Children, 20(2), 87-112.

Wheaton, B. (1990). Life transitions, role histories, and mental health. American Sociological Review, 55(2), 209-223.

Wildeman, C., Wakefield, S., \& Turney, K. (2013). Misidentifying the effects of parental incarceration? A comment on Johnson and Easterling (2012). Journal of Marriage and Family, 75(1), 252-258.

Yoo, H. J. (2015). Living Cohabitation in the Republic of Korea: The Reported Experiences of Lesbians, Gays and Heterosexuals. PhD thesis, University of York.

Yu, T., Petit, G. S., Lansford, J. E., Dodge, K. A., \& Bates, J. E. (2010). The interactive effects of marital conflict and divorce on parent-adult children's relationships. Journal of Marriage and Family, 72(2), 282-292.

Zorn, C. J. W. (2001). Generalized estimating equation models for correlated data: A review with applications. American Journal of Political Science, 45, 470-490.

Publisher's Note Springer Nature remains neutral with regard to jurisdictional claims in published maps and institutional affiliations.

\section{Affiliations}

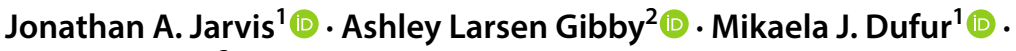 Shana Pribesh ${ }^{3}$}

Ashley Larsen Gibby

ashley_gibby@byu.edu

Mikaela J. Dufur

mikaela_dufur@byu.edu

Shana Pribesh

spribesh@odu.edu

1 Department of Sociology, Brigham Young University, 2008 JFSB, Provo, UT 84602, USA

2 School of Family Life, Brigham Young University, 2063 JFSB, Provo, UT 84602, USA

3 Department of Educational Foundations and Leadership, Old Dominion University, DCOE 2307, Norfolk, VA 23529, USA 